\section{The combined effect of audience and anxiety on paired-associates learning*}

\author{
ALAN S. BERKEY \\ Miami-Dade College, Miami, Fla. 33167 \\ and \\ RONALD A. HOPPE $\dagger$ \\ University of Victoria, Victoria, B.C., Canada
}

\begin{abstract}
Zajonc's (1965) hypothesis was combined with a postulate of general drive theory to predict that the effects of anxiety and an audience would summate to increase the level of drive. Eighty Ss were used in a 2 by 2 by 2 design that had audience, anxiety, and list as factors. For one list competitive responses were high, and for the other they were low. Analysis of variance results and the order of the mean trials to criterion were consistent with the prediction based on the summation hypothesis, e.g., of the eight conditions, the presence of an audience produced the best learning of the noncompetitive list and the poorest learning of the competitive list by high-anxious Ss. However, the lack of significant differences in the learning of the noncompetitive list did not support the summation hypothesis for this task.
\end{abstract}

In 1965 , Zajonc hypothesized that generally the presence of others increases an individual's general drive level, thereby making a dominant response more likely in such a situation than when an individual is alone. He was able to explain the previously puzzling findings that the presence of others was sometimes facilitating and other times interfering. He showed that an audience facilitated performance on simple or well-learned tasks where the dominant response probably would have been appropriate and that, on the other hand, the audience interfered with performance on complex or learning tasks where the dominant response probably would not have been appropriate.

Further specification of the relationship of audience effects to the general drive concept has been recently elaborated by Cottrell (1968, 1972) and by Weiss \& Miller (1971). Following from this approach, another notion of general drive theory is that if different sources of drive, e.g., food deprivation and stress, occur at the same time, then the effects summate to increase the level of drive above that produced by any one source (Hull, 1943; Spence, 1958). The purpose of the present study was to examine the adequacy of the summation notion in explaining the effects of an audience on learning by individuals with different levels of anxiety.

Some evidence exists to support the

* This report is based on a master's thesis that was completed by the first author at Miami University.

tRequests for reprints should be sent to Ronald A. Hoppe, Department of Psychology, University of Victoria, Victoria, B.C.. Canada. summation-of-drive hypothesis. Campbell (1968) and Myers (1969) have found that summation appears to be the best explanation of the performance of rats under irrelevant and relevant drive situations. However, the present research is concerned with what might be considered two different sources of irrelevant drive-audience and anxiety.

Cox $(1966,1968)$ has shown that the presence of an audience facilitates the performance of low-anxious children and interferes with the performance of high-anxious children on a marble-dropping task. Assuming that Zajonc is correct, it appears that these results are inconsistent with a summation hypothesis unless we assume that the task elicited dominant responses in the low-anxious children and nondominant responses in the high-anxious children, which seems unlikely.

Ganzer (1968) found that an unseen audience was detrimental to the learning of high- and middle-anxious Ss but was not detrimental to the learning of low-anxious Ss. These results are not completely consistent with the summation notion, because it would predict that the audience would learning task where the dominant response is incorrect but more detrimental for the high-anxious than the low-anxious Ss.

In the studies by Cox and Ganzer, 1958) was used, and, as has been suggested. this scale may not be assessing a general drive level but rather a specific drive level (Mandler \& Sarason, 1952; Wine, 1971). A specific drive would not be expected to

Results that supported Zajonc's be detrimental for all groups on the the Test Anxiety Scale (Sarason, summate with audience effects. hypothesis for learning and performance were found by Martens (1969) using a complex motor task, but the differences he found in the learning of high- and low-anxious Ss were not consistent with a summation hypothesis. However, his measure of anxiety may not have been appropriate to assess drive differences relevant to the task, as he himself suggests.

Quarter \& Marcus (1971) found that an audience was detrimental to performance on a digit span task but did not find results supportive of a summation hypothesis when the Ss were considered as high and low anxious either using achievement anxiety or affiliative anxiety measures. It is possible that these measures did not assess drive level adequately as it related to the digit span task.

In the present research, a task was chosen that had been previously shown (Spence, Farber, \& McFann, 1956) to be related to the anxiety level of the $\mathrm{S}$, and in another study (Cottrell, Rittle, \& Wack, 1967), performance on the task was shown to be influenced by the presence of an audience.

Spence et al compared the learning of different lists of paired associates by high- and low-anxious Ss. They assumed that the dominant responses were appropriate for learning a list containing few competing responses and inappropriate for learning the list containing many competing responses, and it was also assumed that their measure of anxiety (Taylor Manifest Anxiety Scale, Taylor, 1953) was indicative of the general drive level of the individual. The results were consistent with the expectations derived from general drive theory, i.e., the high-anxious Ss learned the list containing many competing responses more poorly than did the low-anxious Ss.

Cottrell et al examined Zajonc's hypothesis by employing the same competitive and noncompetitive lists used by Spence et al. Cottrell et al argued that if the presence of an audience affects the drive level of the individual, as Zajonc suggested, then Ss who learn the list in the presence of an audience should perform as high-anxious Ss and Ss who learn the lists alone should perform as low-anxious Ss. Their results were in accord with their hypothesis, i.e., the noncompetitive list was learned better and the competitive list was learned more poorly in the presence of an audience than when alone.

General drive theory is broad enough to relate both level of anxiety and the presence of an audience to learning and predicts the learning by high- and low-anxious $S s$ in the 
Table I

P'redicted and Obtained Results for All Conditions of Audience. Ansiety. and List

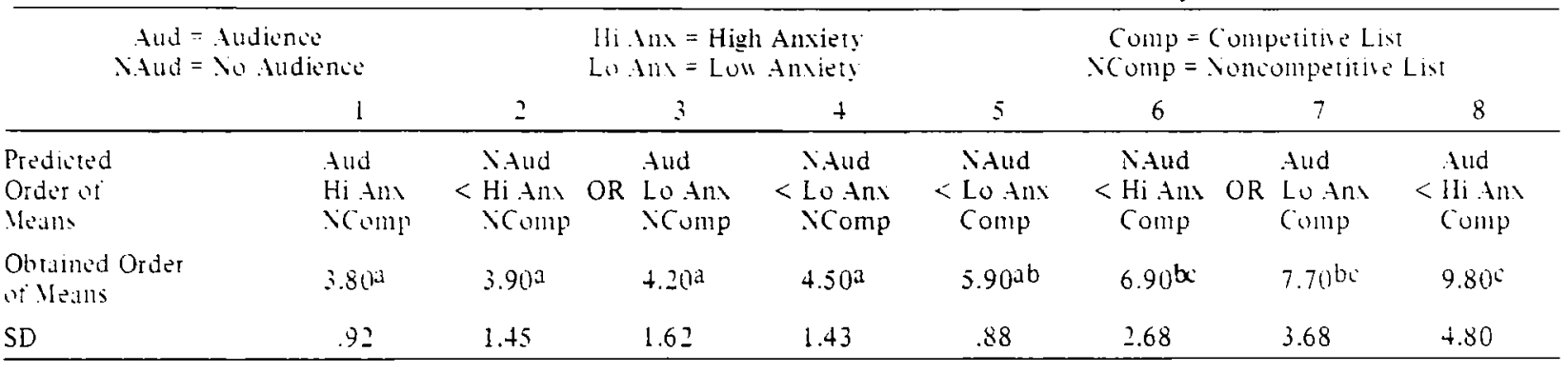

Note-Mians with the same superscript are not significantly different from each other by a one-tailed Venman-Kenls test

presence or absence of an audience if stummation is assumed. This is what was examined in the present study. Essentially. we added the audience factor that Cottrell et al studied to the anxiety and list factors tinat Spence et al studied.

By considering that the drive effects of the audience summate with the anxiety effects to increase the level of drive, as had been suggested earlier, a predicted order of means can be derived. Summation predicts that the level of drive should be the greatest in the high-anxiety audience conditions and the highest level of drive should produce the greatest chance of the dominant responses occurring. Recall that the dominant responses are correct for the noncompetitive list and incorrect for the competitive list. Therefore, the presence of an audience should produce the best learning of the noncompetitive list and thepoorest learning of the competitive list for the high-anxious Ss. The audience should cause the low-anxious $S$ s to learn the noncompetitive list better and the competitive list more poorly than the low-anxious Ss who learn without the audience present. The predicted order, from best to poorest, is as follows: (1) audience present, high-anxious Ss, noncompetitive list; (2) either no audience, high-anxious Ss, noncompetitive list; (3) or audience present. low-anxious Ss. noncompetitive list. Since there is no a priori reason to suppose that individual differences in anxiety are related to more or less drive than the presence of an audience, a difference between 2 and 3 above cannot be predicted. Similarly, no difference between 6 and 7 below can be predicted: (4) no audience, low-anxious Ss, noncompetitive list; (5) no audience, low-anxious Ss, competitive list; (6) either no audience, high-anxious $S$ s, competitive list; ( 7 ) or audience present, low-anxious Ss, competitive list; (8) audience present, high-anxious Ss, competitive list.

\section{METHOD}

The method used in the present study combined the methods of Spence et al and Cottrell et al. Subjects and Design

A 2 by 2 by 2 design having anxiety, audience, and type of list as independent variables was employed. There were $10 \mathrm{Ss}$ in each of the eight cells $(N=80,37$ males, 43 females) selected from the upper and lower $20 \%$ of introductory psychology students on the Taylor Manifest Anxiety Scale.

\section{Procedure}

All $\mathrm{Ss}$ were given six trials on a practice list which was used to familiarize them with the task. Then, using an anticipation method, the Ss were presented with the training list of paired associates on a memory drum which exposed the stimuli at a rate of one every $4 \mathrm{sec}$ ( $2 \mathrm{sec}$ for anticipation and 2 sec for study) and had a 4 -sec interval between successive presentations of the list. For one-half of the Ss, the list was of high associative content - the competitive list-and for the remaining half, the list was of low associative content-the noncompetitive list. These two lists were the same as were employed by Spence et al and Cottrell et al. Fach $S$ learned the list to a criterion of two consecutive perfect trials.

After the Ss had completed the practice list and before they began the training list, one-half of them-those in the audience conditions-were introduced to two students of the same sex as the $S$. The $E$ said simply that these two students had come to observe the experiment. The audience had been briefed beforehand concerning their role and sat quietly in chairs directly behind the $S$ throughout the learning trials. In both the audience and no-audience conditions, the $\mathrm{E}$ was present but was concealed from the $S$ during the learning trials.

\section{RESULTS AND DISCUSSION}

The dependent measure was trials to criterion. No reliable sex differences were found, so the data from men and women were combined.

Heterogeneity of variance was present $\left(F_{\text {max }}=30.10 . p<01\right)$, but there was no evidence that any of the distributions were truncated. Therefore, a 2 by 2 by 2 analysis of variance was performed, using audience, anxiety, and list as factors and trials to criterion as the dependent measure. There was a significant main effect for the list factor $(F=37.10$, $d f$ $=1,72, p<.01$ ), indicating that the competitive list was more difficult than the noncompetitive list. The interaction between list and audience was significant $(F=5.00, \mathrm{df}=1,72$, $\mathrm{p}<.05)$, and the interaction between list and anxiety approached significance $(\mathrm{F}=3.23, \mathrm{df}=1.72$, $p=.08$ ). Additional 2 by 2 analyses of variance within the list, audience, and anxiety factors indicated that the audience produced a significant effect in the learning of the competitive list $(F=4.95, \mathrm{df}=1,36, \mathrm{p}<.05)$ but not in the learning of the noncompetitive list. The anxiety factor was not significant in either the competitive or noncompetitive list. The nature of the interactions can be seen by examining Table 1. The trend suggests that high anxiety and the presence of an audience hindered the learning of the competitive list but showed only slight and insignificant help in the learning of the noncompetitive list.

The directional comparisons of the means (see Table 1) and the results of the analyses of variance offer some support for the hypothesis that anxiety and audience effects summate when considering the competitive list, but the predicted differences are not significant when considering the noncompetitive list. However, comparing the predicted order of means with the obtained order yields a perfect correlation ( $r$ ho $=1.00$ ) which strongly supports the summation hypothesis.

The lack of significant differences within the noncompetitive list might be because anxiety and audience drive effects are not operative during the learning of a simple task or, more simply, because the noncompetitive list might be too easy for today's college students so that there is not sufficien: variation in performance to 
permit the drive effects of audience and anxiety to be demonstrated. This is consistent with the findings of Cottrell, Rittle, \& Wack (1967), who also found only slight and nonsignificant audience effects on the learning of the noncompetitive list.

In summary, using individual differences in anxiety and the presence or absence of an audience, two kinds of learning performance were examined. A predicted order of means based on a drive summation hypothesis was obtained in the results. However, the lack of significant differences in the learning of the easy task did not support the hypothesis that anxiety and audience effects summate to influence the learning of an easy task.

\section{REFE.RENCES}

CAMPBELL, B. A. Interaction of aversive stimuli: Summation or inhibition. Journal of Experimental Psychology, 1968, 78, 181-190.

COX, F.N. Some effects of test anxiety and presence or absence of other persons on boys' performance on a repetitive motor task. Journal of Experimental Child Psuchology, 1966, 3, 100-112.
COX, F. N. Some relationships between test anxiety, presence or absence of male persons, and boys' performance on a repetitive motor task. Journal of Experimental Child Psychology, 1968, 6. $1-12$

COTTRELL, N. B. Performance in the presence of others. In E. C. Simmel, R. A. Hoppe, and G. A. Milton (Eds.), Social facilitation and imitative behavior. Boston: Allyn \& Bacon, 1968.

COTTRFi,L, N. B. Social facilitation. In C. $G$. M cClintock (Ed.). Experimental social psychology. New York: Holt, Rinehart \& Winston, 1972.

COTTRFLL, N. B., RITTLE, R. H., \& WACK, D. L. Presence of an audience and list type (competitional or noncompetitional) as joint determinants of performance in paired-associates learning. Journal of Personality, 1967. $35,425-434$.

GANZER, V. J. Effects of audience presence and test anxiety on learning and retention in a serial learning situation. Journal of Personality \& Social Psychology, 1968, 8. 194-199.

HULL, C, L. Principles of behavior. New York: Appleton-Century-Crofts, 1943.

MANDLER, G., \& SARASON, S. B. A study of anxiety and learning. Journal of Abnormal \& Social Psychology, 1952, 47 , 166-173.

MARTENS, $R$. Effect of an audience on learning and performance of a complex motor skill. Journal of Personality \& Social Psychology, 1969, 12, 252-260.
MYERS. A. K. Effects of continuous loud noise during instrumental shock-escape conditioning. Journal of Comparative \& Physiological Psychology, 1969, 68, 617-622.

QLARTER, J \& MARCUS, A. Drive level and the audience effect: $A$ test of $Z$ ajonc's theory. Journal of Social Psychology, 1971, 83, 99-105.

SARASON, I. G. Interrelationships among individual difference variables, behavior in psychotherapy and verbal conditioning. Journal of Abnormal \& Social Psychology, 1958, 56, 339-344.

SPENCE, $K$, W A theory of emotionally based drive (D) and its relation to performance in simple learning situations. American Psychologist, 1958, 13, 131-141.

SPENCE, K. W., FARBER, I. E., \& MCFANN, H. H. The relation of anxiety (drive) level to performance in competitional and noncompetitional paired-associates learning. Journal of Experimental Psychology, 1956, 52. 296-305.

TAYLOR, J. A. A personality scale of manifest anxiety. Journal of Abnormal \& Social Psychology, 1953, 48, 285-290.

WEISS, R. F., \& MILLER, F. G. The drive theory of social facilitation. Psychological Review, 1971, 78, 44-57.

WINE, J. Test anxiety and direction of attention. Psychological Bulletin, 1971, 76, 92-104

ZAJONC, R. B. Social facilitation. Science, $1965,149,269-274$. 